\title{
Rheological Study on Different Gum Solutions
}

\author{
Pooja Sahu $^{1 *}$, P.S. Pisalkar ${ }^{1}$, S. Patel ${ }^{1}$ and Pratibha Katiyar ${ }^{2}$ \\ ${ }^{1}$ Department of Agricultural Processing and Food Engineering, SVCAET \& RS, \\ FAE, IGKV, Raipur-492012, Chhattisgarh, India \\ ${ }^{2}$ Department of Plant Physiology, Agri. Bio-chemistry \& Medicinal Aromatic Plants, \\ IGKV, Raipur-492012, Chhattisgarh, India \\ *Corresponding author
}

\section{A B S T R A C T}

\begin{tabular}{|c|}
\hline Keywords \\
\hline $\begin{array}{l}\text { Rheology, } \\
\text { Viscosity, } \\
\text { Concentration, Gum }\end{array}$ \\
\hline Article Info \\
\hline $\begin{array}{l}\text { Accepted: } \\
28 \text { April } 2020 \\
\text { Available Online: } \\
10 \text { May } 2020\end{array}$ \\
\hline
\end{tabular}

In the present investigation, rheological properties (viscosity) of different gum like Karaya, Babool, Anogiessus latifolia, Acacia nelotica and Acacia Senegal were found by Brookfield viscometer and compare its swelling capacity. Mucilages containing 1 to $10 \%$ $\mathrm{w} / \mathrm{v}$ of different gum were prepared by dispersing in freshly distilled water and allowed to stand undisturbed for $24 \mathrm{~h}$ for complete hydration. The viscosity and shear stress were recorded at different speeds, ranging from 0.5 to $100 \mathrm{rpm}$ at room temperature $\left(28-30^{\circ} \mathrm{C}\right)$. The viscosity of gums increases with the increased in the concentration (1 to 5\%) in the entire gum specimen (Acacia Senegal, Anogiessus latifolia, Acacia nelotica and Sterculia urens Roxb.). In Acacia Senegal, Anogiessus latifolia and Acacia nelotica gum, variation in viscosity with shear rate is very less i.e. nearly constant and exhibited a Newtonian behaviour. In Karaya gum, viscosity decreased with the increased in shear rate and exhibited pseudoplastic (shear thinning) behaviour. Karaya gum has higher capacity to form viscous solutions and gels at low concentration as compare to Acacia Senegal, Anogiessus latifolia, Acacia nelotica gum.

\section{Introduction}

Gums, natural plant hydrocolloids are important products that are used as stabilizers, thickeners, binders etc. in various industries such as paper, textile, paint, ink, food, cosmetic, and petroleum industries. They are also used in pharmaceutical industry as thickening, binding, disintegrating agents and as coating material in microencapsulation. The vast application of the plant gums in various industries is because of low cost, easy availability and the important properties which they contribute to products. As a result of this the demand for natural gums has greatly increased.

Gum Karaya is a polysaccharide of high molecular weight which on hydrolysis yields D-galactose, L-rhamnose, and D-galacturonic acid, together with minor amounts of Dglucuronic acid. A significant feature of Gum 
Karaya is the presence of acetic acid in the polysaccharide. Karaya Gum in the dry state is not soluble in water but only forms viscous suspensions. The gum enormously swells in water and forms thick suspensions. Viscosity and swelling factor play a key role in the utilization of gum for various purposes.

Gum Karaya finds major application in bulk laxatives, denture adhesives, colostomy appliances and in appetite suppressants. Viscosity and swelling ability of the gum decides the quality of gum in industrial applications. There are applications of importance other than those mentioned above like food additives and ice cream stabilizers. A substantial quantity of the gum is exported from India while only a small percentage is indigenously used.

The gum obtained from Acacia nilotica is known as "Indian gum arabic". The gum is tasteless and almost completely soluble in water $(50 \mathrm{~g} / 100 \mathrm{ml})$. Its molecular weight is $2.3 \times 10^{6}$. The gum contains galactose, Larabinose, L-rhamnose, and four aldobiouronic acids. The viscosity of 30 percent of A. Nilotica at shear rate of $9.6 \mathrm{~s}^{-1}$ was found to be $120 \mathrm{cps}$ Viscosity of both the gums decreases as the shear rate increases. Therefore it is termed as psuedoplastic material. It has been found that gum arabica shows high value of ionic conductivity after swelling which may be due to release of ions during swelling

Dhawdha gum also known as Indian gum and is exudates from Anogeissus latifolia tree. The tree is characteristic of the dry, deciduous forests and is common almost throughout India. It contains moisture $15.8 \%$, pentosan $26.3 \%$, methyl pentosan $7.6 \%$, galactan $16.4 \%, \mathrm{~N} 0.99 \%$, ash $3.0 \%$ and riboflavin $68.92 \mu \mathrm{g} / \mathrm{g}$. It is a calcium and magnesium salt of an acidic polysaccharide composed of Larabinose, D-galactose, D-mannose, Dxylose and D-glucuronic acid in a molar ratio of 10:6:2:1:2. It forms viscous dispersions in water when a concentration is $5 \%$ or more. The dispersions are thixotropic and nonNewtonian in behaviour. It has good emulsifying properties.

The viscosity of gum is an important factor having an influence on the processing conditions and quality of the final product in which they are incorporated. The viscosity of a gum solution is a major parameter influencing the mouth feel, organoleptic properties, and acceptability. Knowledge of the flow properties and rheological parameters of pharmaceutical adjuvant is of great importance and finds its applications in the formulation and analysis of pharmaceutical products such as emulsion, suspension, paste, suppositories, and tablet coatings. The rheology of a product can affect not only patient acceptability, but can also influence the choice of processing equipments to be used in its manufacture. The mucilages of natural and synthetic gums which include majority of suspending agents are pseudoplastic in nature. Rheological properties of gum are important criteria in deciding its commercial use.

\section{Materials and Methods}

\section{Materials}

The viscometer was digital Brookfield DV-E viscometer (Brookfield Engineering Laboratories Inc., USA). The gum samples of Karaya were collected from the forest area of Gariyaband and Babool samples were collected from Naya Raipur area. The gum samples of Acacia Senegal and Dhawdha (Anogiessus latifolia) was procured from the local market of Raipur. A collected and procured sample of gums was first cleaned and then grinds with the help of grinder. The crushed samples were sieved between 8 and 30 mesh is taken for viscosity. 


\section{Methods}

\section{Rheological behavior}

\section{Sample preparation}

Mucilages containing 1 to $10 \% \mathrm{w} / \mathrm{v}$ of different gum were prepared by dispersing in freshly distilled water and allowed to stand undisturbed for $24 \mathrm{~h}$ for complete hydration.

\section{Measurement}

The viscosity of gum solutions was measured on Brookfield viscometer at room temperature $\left(28-30^{\circ} \mathrm{C}\right)$ using Spindle No. 61 and 62. The viscosity and shear stress were recorded at different speeds, ranging from 0.5 to 100 $\mathrm{r} / \mathrm{min}$. Digital reading was recorded after shearing the mucilage at each speed for exactly $1 \mathrm{~min}$.

\section{Results and Discussion}

In table 1 shows that variation in viscosity with different concentration of gum solution and rotational speed in Acacia Senegal gum. It has been observed that viscosity increases with different concentration i.e. 1, 2, 3, 4 and $5 \%$ solution in Acacia Senegal gum and decreases with respect to rotational speed $(100,50,20,10,5 \mathrm{rpm})$ with the spindle (no. 62).

In table 1 shows that variation in viscosity with different concentration of gum solution and rotational speed Dhawdha (Anogiessus latifolia) gum. It has been observed that viscosity increases with different concentration i.e. 1, 2, 3, 4 and 5\% solution in Dhawdha (Anogiessus latifolia) gum and decreases with rotational speed $(100,50,20$, 10 and $5 \mathrm{rpm}$ ) with the spindle (no. 62).

In the table 3 shows that variation in viscosity with different concentration of gum solution and rotational speed in Babool gum (Acacia nelotica). It has been observed that in Babool (Acacia nelotica) gum, viscosity was increases with different concentration (i.e. 1, 5, 10 and 20\% solution) and decreases with rotational speed $(100,50,20,10,5,4,2.5,2$, 1 and $0.5 \mathrm{rpm}$ ) with the spindle (no. 61). For this gum, solution concentration taken 1, 5, 10 and $20 \%$ because swelling power very low compare to other gum solution.

Table.1 Variation in viscosity with different concentration of gum solution and rotational speed in Acacia Senegal gum

\begin{tabular}{|c|c|c|c|c|c|}
\hline $\begin{array}{l}\text { Acacia Senegal } \\
\text { Spindle number -62 }\end{array}$ & \multicolumn{5}{|c|}{ Viscosity with different concentration, (cp) } \\
\hline Rotational Speed, (rpm) & $\mathbf{1 \%}$ & $\mathbf{2 \%}$ & $\mathbf{3 \%}$ & $\mathbf{4 \%}$ & $\mathbf{5 \%}$ \\
\hline $\mathbf{1 0 0}$ & 168.3 & 167.7 & 166.8 & 166.0 & 178.5 \\
\hline $\mathbf{5 0}$ & 4.20 & 3.60 & 5.40 & 4.80 & 6.00 \\
\hline $\mathbf{2 0}$ & 4.50 & 3.00 & - & 1.50 & 4.50 \\
\hline $\mathbf{1 0}$ & 6.00 & 1.50 & - & - & 3.00 \\
\hline $\mathbf{5}$ & 6.00 & - & - & - & - \\
\hline
\end{tabular}


Table. 2 Variation in viscosity with different concentration of gum solution and rotational speed in Dhawdha (Anogiessus latifolia) gum

\begin{tabular}{|c|c|c|c|c|c|}
\hline $\begin{array}{l}\text { Dhawdha (Anogiessus latifolia) } \\
\text { Spindle number -62 }\end{array}$ & \multicolumn{5}{|c|}{ Viscosity with different concentration, (cp) } \\
\hline Rotational Speed, (rpm) & $\mathbf{1 \%}$ & $\mathbf{2 \%}$ & $\mathbf{3 \%}$ & $\mathbf{4 \%}$ & $\mathbf{5 \%}$ \\
\hline $\mathbf{1 0 0}$ & 193.5 & 154.5 & 198.3 & 199.7 & 200.9 \\
\hline $\mathbf{5 0}$ & 1.20 & 4.20 & 2.40 & 4.80 & 5.40 \\
\hline $\mathbf{2 0}$ & - & 3.00 & - & 3.00 & 4.50 \\
\hline $\mathbf{1 0}$ & - & 3.00 & - & - & 3.00 \\
\hline $\mathbf{5}$ & - & - & - & - & - \\
\hline
\end{tabular}

Table.3 Variation in viscosity with different concentration of gum solution and rotational speed in Babool gum (Acacia nelotica)

\begin{tabular}{|c|c|c|c|c|}
\hline $\begin{array}{l}\text { Babool gum (Acacia nelotica) } \\
\text { Spindle number 61 }\end{array}$ & \multicolumn{4}{|c|}{ Viscosity with different concentration, (cp) } \\
\hline Rotational Speed, (rpm) & $\mathbf{1 \%}$ & $\mathbf{5 \%}$ & $\mathbf{1 0 \%}$ & $\mathbf{2 0 \%}$ \\
\hline $\mathbf{1 0 0}$ & 3.54 & 5.4 & 9.3 & 42.6 \\
\hline $\mathbf{5 0}$ & 2.28 & 3.72 & 7.56 & 42.36 \\
\hline $\mathbf{2 0}$ & 1.2 & 2.7 & 6.3 & 43.2 \\
\hline $\mathbf{1 0}$ & 1.2 & 1.8 & 5.4 & 42.6 \\
\hline $\mathbf{5}$ & 0.6 & 1.2 & 2.4 & 42.0 \\
\hline $\mathbf{4}$ & - & 1.5 & 1.5 & 42.0 \\
\hline $\mathbf{2 . 5}$ & - & - & 2.4 & 43.2 \\
\hline $\mathbf{2}$ & - & - & 1.2 & 39.0 \\
\hline $\mathbf{1}$ & - & - & - & 24.0 \\
\hline $\mathbf{0 . 5}$ & - & - & - & 36.0 \\
\hline
\end{tabular}

Table.4 Variation in viscosity with different concentration of gum solution and rotational speed in Karaya gum (Sterculia urens Roxb)

\begin{tabular}{|c|c|c|c|c|c|}
\hline \begin{tabular}{|c|c|c|} 
Karaya gum (Sterculia urens Roxb.) \\
Spindle number 61
\end{tabular} & \multicolumn{4}{|c|}{ Viscosity with different concentration, (cp) } \\
\hline Rotational Speed, (rpm) & $\mathbf{1 \%}$ & $\mathbf{2 \%}$ & $\mathbf{3 \%}$ & $\mathbf{4 \%}$ & $\mathbf{5 \%}$ \\
\hline $\mathbf{6 0}$ & 56.4 & 64.32 & 50.4 & 66.48 & 55.8 \\
\hline $\mathbf{3 0}$ & 8.6 & 159.00 & 100.2 & 160.5 & 100.8 \\
\hline $\mathbf{1 2}$ & 16.0 & 184.80 & 253 & 315.6 & 271 \\
\hline $\mathbf{6}$ & 31.0 & 366.80 & 501 & 610.8 & 507 \\
\hline $\mathbf{3}$ & 50.0 & 636.20 & 1006 & 1205 & 1024 \\
\hline $\mathbf{1 . 5}$ & 100.0 & 747.00 & 2004 & 1509 & 2020 \\
\hline $\mathbf{0 . 6}$ & 510.0 & 1176.00 & 5000 & 3000 & 5010 \\
\hline $\mathbf{0 . 3}$ & 880.0 & 2556.00 & 10000 & 6012 & 10040 \\
\hline
\end{tabular}




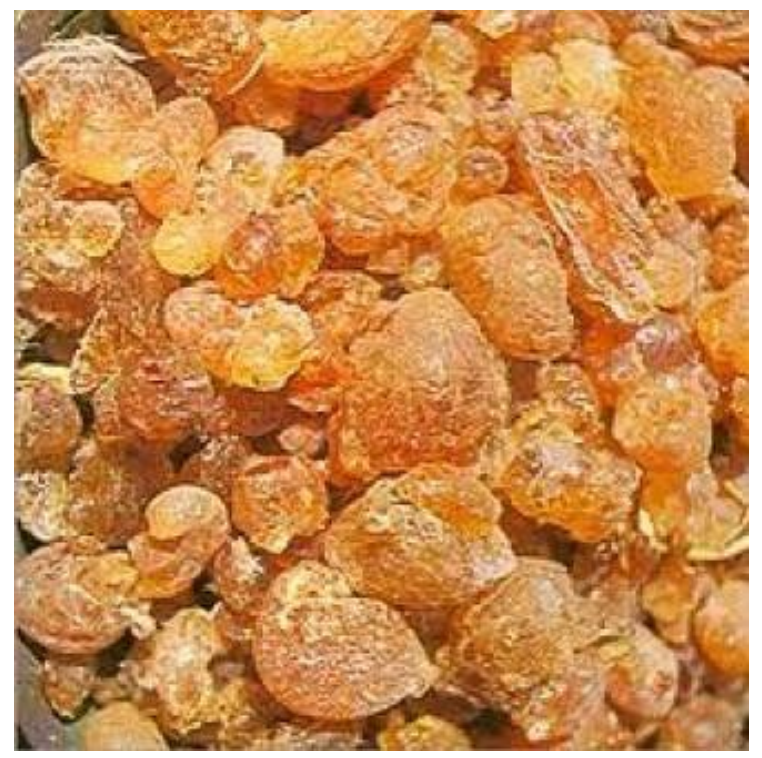

Fig. 1. Babool gum (Acacia nelotica)

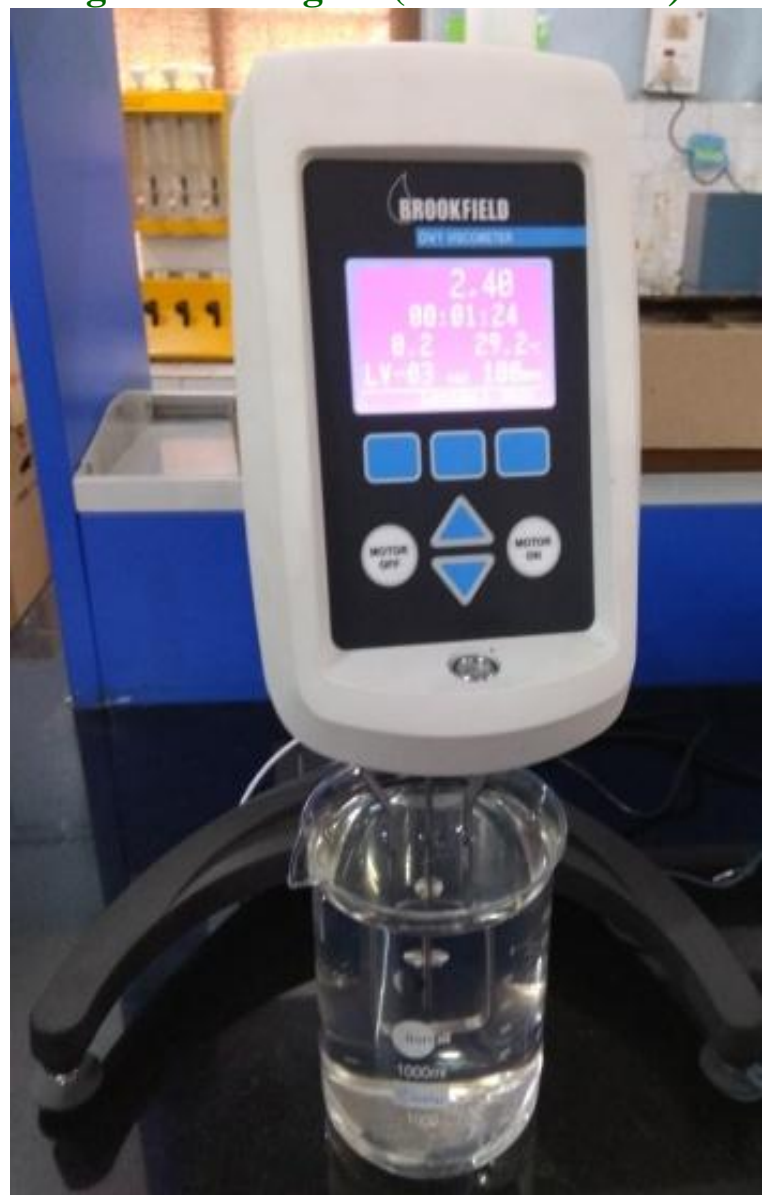

Fig.3 Brookfield Viscometer (DV-E)

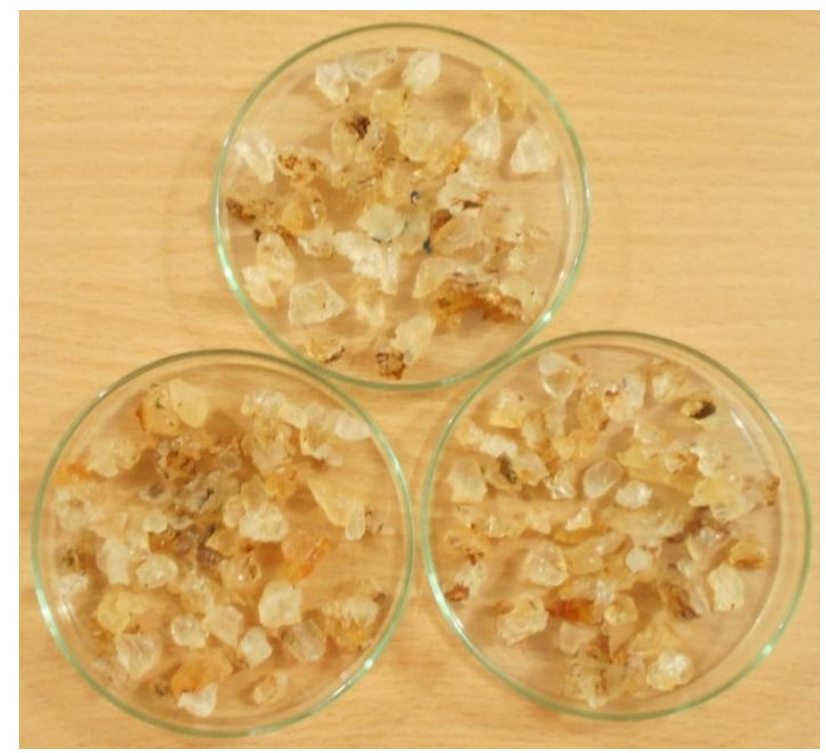

Fig. 2. Karaya gum (Sterculia urens Roxb.)

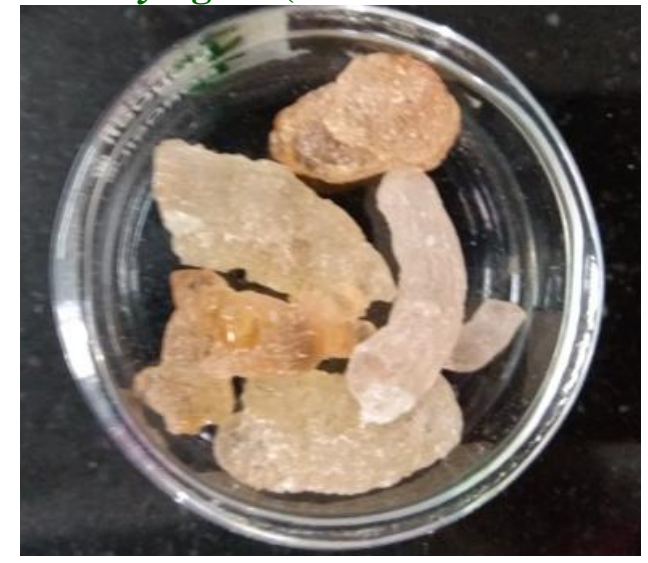

Fig. 4. Acacia senegal

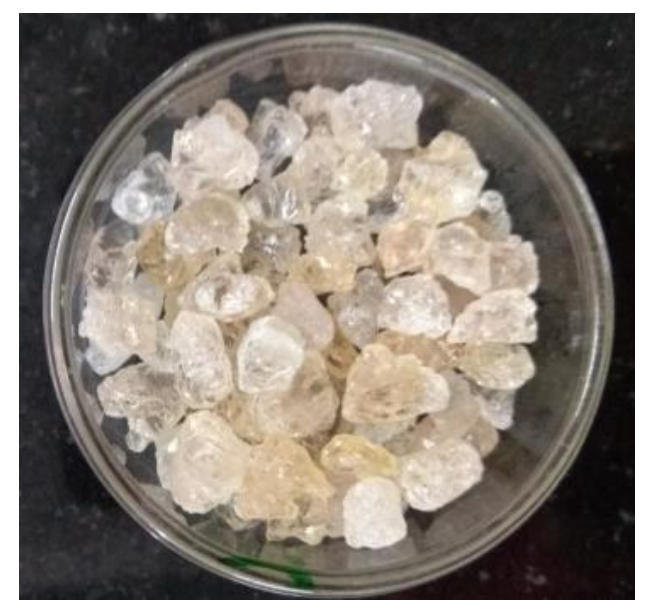

Fig.5 Anogiessus latifolia 


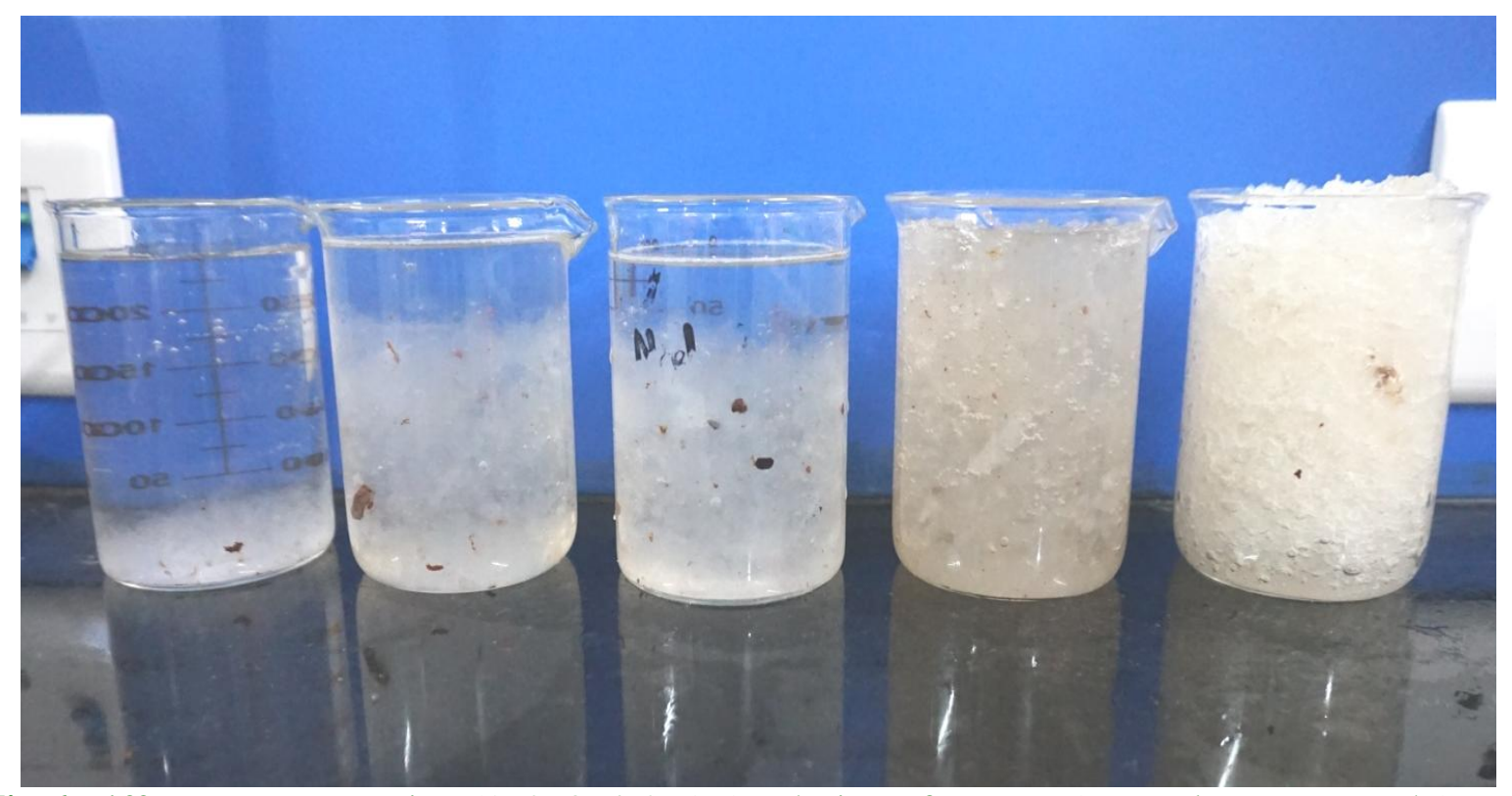

Fig.6 Different concentration (1, 2, 3, 4 \& 5\%) solution of Karaya (Sterculia urens Roxb.) gum

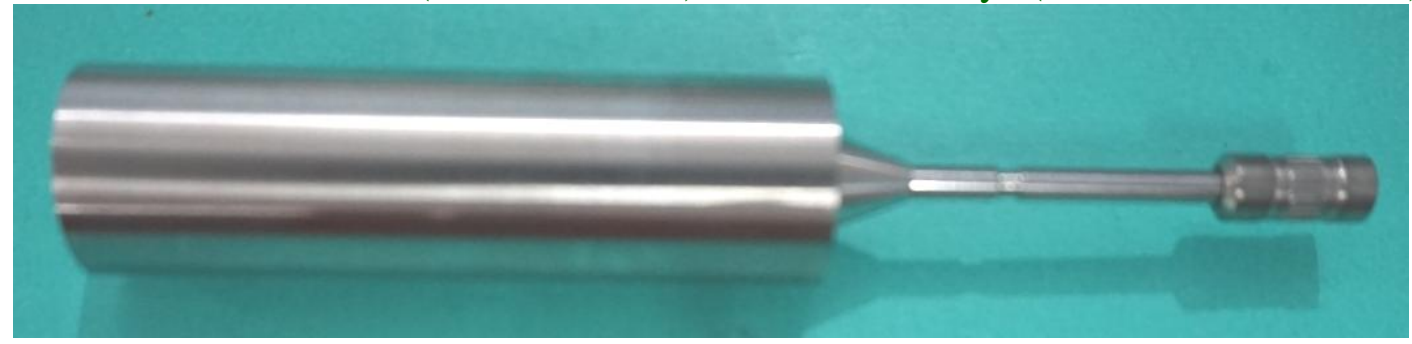

Fig. 7. Spindle number 61

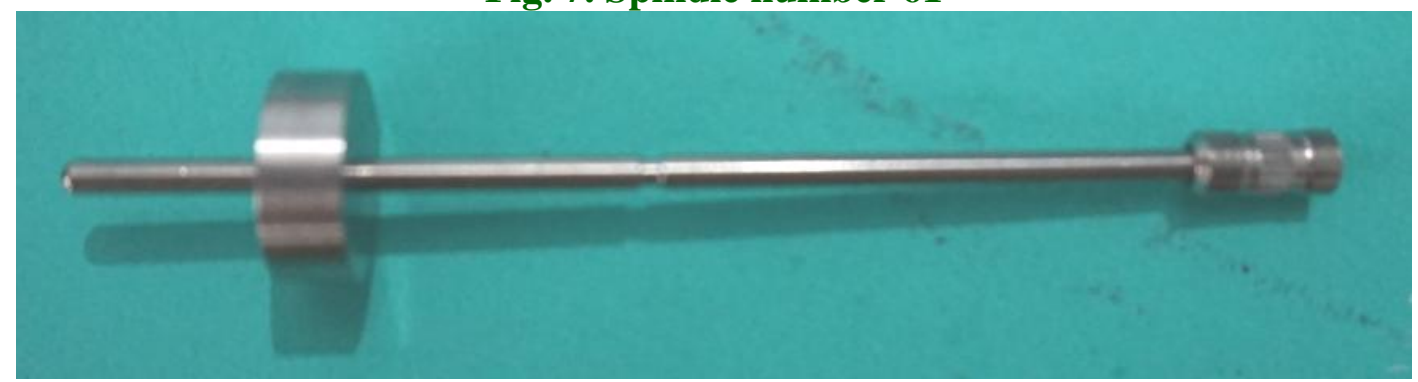

Fig.8 Spindle number 62

In the table 4 shows that variation in viscosity with different concentration of gum solution and rotational speed in Karaya gum (Sterculia urens Roxb). It has been observed that in Karaya gum (Sterculia urens Roxb), viscosity was not changed in frequent interval with different concentration (i.e. 1, 2, 3, 4 and 5\% solution) and increases with rotational speed $(60,30,12,6,3,1.5,0.6$ and $0.3 \mathrm{rpm})$ with the spindle (no. 61). For this gum, solution concentration taken 1, 2, 3, 4 and $5 \%$ because swelling power very high as compare to other gum solution. Consequently, viscosity decreased with the increased in shear rate and exhibited pseudoplastic (shear thinning) behaviour.

In conclusion, the viscosity of gum increases with the increased in the concentration (1 to $5 \%$ ) in all the gum specimen (Acacia Senegal, Anogiessus latifolia, Acacia nelotica and Sterculia urens Roxb.). In Acacia Senegal, 
Anogiessus latifolia and Acacia nelotica gum, variation in viscosity with shear rate is very less i.e. nearly constant and exhibited a Newtonian behaviour. In karaya gum, viscosity decreased with the increased in shear rate and exhibited pseudoplastic (shear thinning) behaviour. Karaya gum has higher capacity to form viscous solutions and gels at low concentration as compare to Acacia Senegal, Anogiessus latifolia, Acacia nelotica gum.

\section{Acknowledgements}

The authors are grateful to the Department of Agricultural Processing and Food Engineering, Swami Vivekananda College of Agricultural Engineering and Technology and Research Station, Faculty of Agricultural Engineering, Indira Gandhi Krishi Vishwavidyalaya, Raipur (Chhattisgarh) for moral support and to provide essential facility.

\section{References}

Adeleye, Olutayo A., Femi-Oyewo, Mbang N., and Odeniyi, Michael A. 2015. Physicochemical and Rheological characterization of Cissus Populnea Gum Extracted by Different Solvents. West African J. of Pharmacy 26 (1) 113-126.

Ameh, Paul Ocheje. 2012. Physicochemical Properties and Rheological Behavior of Ficus glumosa Gum in Aqueous Solution. International J. of Modern Chemistry 2(3): 84-99.

Eddy, Nnabuk O., Ameh, Paul O., Gimba,
Casimir E. and Ebenso, Eno E. (2012) Rheological Modeling and Characterization of Ficus platyphylla Gum Exudates. J. Chemistry. Pp. 1-10.

Farahnaky, A., N., Darabzadeh, M., Majzoobi, Gh., Mesbahi, E., Rezvani and G., Schleining. (2013). Production and rheological properties of locust bean gum from Iranian carob seeds. Insidefood symposium. 1-6.

Higiro, J., Herald, T.J. and Alavi, S. (2005). Rhelogical Study of Xanthan and Locust Bean Gum Interaction in Dilute Solution. Food Research International. (39) 165-175.

Munoz, Jose, Rincon, Fernando, Alfaro, M. Carmen, Zapata, Isabel, Fuente, Julia de la, Beltran, Olga and Pinto, Gladys Leon de. 2007. Rheological Properties and Surface Tension of Acacia tortuosa Gum Exudate Aqueous Dispersion. Carbohydrate Polymers 70 (2007) 198205.

Sarathchandiran, I., and Suresh Kumar, P. (2014). Characterization and Standardization of Gum Karaya. International J. of Biopharmaceutics. 5(2) 142-151.

Shekarforoush, Elhamalsadat, Mirhosseini, Hamed, Amid, Bahareh Tabatabaee, Ghazali, Hasanah, Muhammad, Kharidah, Sarker, Zaidul Islam and Paykary, Maryam. (2015). Rheological Properties and Emulsifying Activity of Gum Karaya (Sterculia urens) in Aqueous System and Oil in Water $(\mathrm{O} / \mathrm{W})$ Emulsion: Heat Treatment and Microwave Modification. International J. Food Properties. Pp. 1-47.

\section{How to cite this article:}

Ambily, R., M. Kour, M. Shynu, B. Bhatia and Aravindakshan, T. V. 2020. Evaluation of Antibacterial Activity of Laccase from Bacillus subtilis. Int.J.Curr.Microbiol.App.Sci. 9(05): 3482-3488. doi: https://doi.org/10.20546/ijcmas.2020.905.413 